\title{
Drive effects on instrumental response speed induced by intermittent disagreement in conversation
}

\author{
ROBERT FRANK WEISS, FRANKLIN G. MILLER, \\ MICHELE K. STEIGLEDER, and DAYLE A. DENTON \\ University of Oklahoma, Norman, Oklahoma 73019
}

\begin{abstract}
Participation in conversation in which a subject encounters disagreeing opinions is aversively motivated by the disagreement and reinforced by the opportunity for the subject to speak in reply. In an experimental conversation modeled on discrete-trials instrumental conditioning, instrumental response speeds were faster when conversation began with disagreement on every trial rather than half of the trials, as in escape-conditioning studies of intermittent shock $(N=58, p<.005)$.
\end{abstract}

Subjects will learn an instrumental response, the reinforcement for which is the opportunity to speak in reply to a person of differing opinion. Latency data from nine experiments show a fundamental similarity to a discretetrials instrumental escape-conditioning model in demonstrating replicable analogs of (1) acquisition, (2) extinction, (3) partial-reinforcement effects, (4) drive effects, (5) a delay of reinforcement gradient, (6) correlated reinforcement effects, (7) correlated delay of reinforcement effects, and (8) intermittent shock effects (Weiss, Beck, \& Stich, 1972; Weiss, Boyer, Colwick, \& Moran, 1971; Weiss, Lombardo, Warren, \& Kelley, 1971; Weiss, Williams, \& Miller, 1972). The importance of studying one person's reply to another is generally acknowledged by researchers in interpersonal communication, but the reinforcing function of speaking in reply had not previously been identified and explored. Is replying a positive reinforcement like the presentation of food in instrumental reward conditioning, or is it a negative reinforcement like the reduction of shock in escape conditioning? Positive or negative reinforcement, appetitive or aversive motivation: For a basic form of interpersonal communication the question is not a trivial one. The subjects reply to statements which disagree with their own opinions. Theory and research indicate that (1) disagreement induces and (2) replying reduces aversive drive, as in escape conditioning. With regard to drive induction, Dollard and Miller (1950, pp. 116-124) have described learned drives based on social punishment and frustration of behavior which is insufficiently logical, lacks explanation, or fails to make a logical report of the environment. Byrne and his associates (e.g., Byrne, 1971; Byrne \& Clore, 1967) have further developed these concepts under the name of effectance drive and have exploited their implications

Reprints may be obtained from R. F. Weiss, Department of Psychology, University of Oklahoma, Norman, Oklahoma 73019. for attraction and related social processes. Their work, and others', indicates that the aversive drive of effectance can be aroused by opinions which are dissimilar to the subject's own (e.g., Byrne \& Clore, 1967) or by disagreement with the subject by other persons (e.g., Lombardo, Weiss, \& Buchanan, 1972; Stapert \& Clore, $1969)$ and that the presentation of such opinion statements following a response is punishing in discrimination learning (e.g., Byrne, Griffitt, \& Clore, 1968) and conditioning (Lombardo, Weiss, \& Buchanan, 1972). Moreover, effectance induced by prior disagreement with other persons exhibits the characteristic differential energizing effect of drive on dominant and competing responses in paired associates learning (Lombardo, Libkuman, \& Weiss, 1972). The conversation studies of Weiss and his co-workers indicate that replying reduces this drive: Replying increases attraction toward the disagreer (Lombardo, Weiss, \& Stich, 1973) and, most directly, the results of the conditioning studies include partial-reinforcement acquisition effects and drive-reinforcement interaction effects which are specifically characteristic of escape rather than reward conditioning (Weiss, Lombardo, Warren, \& Kelley, 1971).

Another escape-conditioning variable which does not parallel reward-conditioning research is intermittent shock (e.g., Franchina, 1969). The subject is shocked on only some of the trials and still performs the response, but more slowly than subjects who receive shock on all trials. A conversational analog of intermittent shock (initial disagreement on only some trials) offers the opportunity not only to distinguish between escape and reward, but also to pinpoint the locus of the aversive drive in the disagreeing opinion. It therefore follows that subjects disagreed with at the outset of only half of the trials should still perform the instrumental response, but more slowly than subjects disagreed with at the beginning of all trials. This prediction was confirmed in an experiment by Weiss, Williams, and Miller 
(1972). The purpose of the present experiment is to demonstrate the replicability of the effect and the independence of the effect from adventitious specifics of procedure.

\section{METHOD}

\section{Shock Manipulation}

Nonshock (nondisagreement) cannot appropriately be manipulated by the substitution of agreeing opinions for disagreeing ones, particularly because of the role of agreeing opinions as positive reinforcers (e.g., Byrne, 1971; Lamberth, Gouaux, \& Davis, 1972); the following simple procedure suggested itself as a close analog of shock vs. nonshock trials. The "other person" in the conversation was represented to the subject as having been provided with a list of topics. On each trial the other person read the topic and, on shock trials only, offered an opinion known to disagree with the subject's own. The subject then had an opportunity to comment on the other person's statement if he wished. Nonshock trials followed the identical procedure, except that the disagreeing opinion was omitted and the subject commented on the topic if he wished. The continuous shock group received the topic-and-disagreeingopinion on all trials, while the intermittent shock group received the topic-and-disagreeing-opinion on only half of the trials and the topic alone on the other half. Four different orders of intermittent shock were employed.

\section{Conditioning}

The subjects performed an instrumental response of switchpressing, the reinforcement for which was the opportunity to speak in reply.

The subject was seated at a table facing the control room wall, which included four one-way vision windows. Instructional signals appeared in each window upon illumination. The signals were the large printed words (1) "listen," (2) "throw switch if you wish to comment." (3) "talk," and (4) "move dial to final opinion." A panel mounted on the table top contained the subject's "comment" switch (a telephone toggle switch with a spring return), his intercom, and a dial used in the masking task.

An experimental trial began with the "listen" signal, followed by the other person's statement. When the statement ended, the experimenter operated the control which both (1) presented the CS, the signal "throw switch if you wish to comment," and (2) started the latency timer. When the subject threw the comment switch, the latency timer automatically stopped, measuring latency to $.01 \mathrm{sec}$. The "talk" signal followed the switch-press response and the subject spoke in reply. The procedure described was closely modeled on discrete-trials instrumental conditioning. The reinforcement (speaking in reply) was contingent on the instrumental response (switch-pressing). The dependent variable was speed (100/latency) measured from the time of the presentation of the CS (signal "press switch if you wish to comment") to the instrumental switch-pressing response.

\section{Deception and Masking Task}

The experiment was represented to the subjects as a study of opinion change: "We are interested in how your opinion may be affected by what someone else says: how your opinion may be affected by what you yourself say: and how what you say may affect the opinions of someone else." As a masking task, after each trial the subject indicated whether he had changed his opinion by moving a dial. Questionnaire data (Weiss, Lombardo, Warren, \& Kelley, 1971) showed that the subjects believed this deception: The switch appeared to them as a mere incidental to the serious business of opinion change through conversation.

\section{Subjects and Materials}

The subjects were 58 undergraduates. The opinions expressed by the "other person" were selected by means of a 25 -item questionnaire administered to each subject just before the experimental session. The subjects indicated their opinions on each item and ranked the 12 items of greatest interest from among those on which they had an opinion. In the eight previously reported reply experiments, the "other person" was simulated by a tape recorder. The logic of the intermittent shock manipulation produced a situation in which the subject never encountered the occasional initial agreement which had been deliberately included in previous studies. Uniformity of disagreement may be given a theoretical interpretation as a process or a boundary condition. At the inception of the present study, however, even greater emphasis was placed on peculiarities of the particular tapes employed in the previous intermittent shock study noted by Weiss, Williams, and Miller (1972, p. 343). "These tapes were different from the ones used in all previous studies and were intended particularly for studies in which it was desirable to have complete uniformity of disagreement or agreement, together with a structure which made it possible (together with another hundred tapes) to closely specify the strength of the argument. Ironically, the structure of these meticulously prepared tapes made them intimidatingly logical, resulting over several studies in a pattern of shallow or flat acquisition curves following rapid differentiation between the experimental groups." Highly controlled techniques for the use of live confederates, rather than tape recordings, have been developed and refined in this laboratory for the investigation of conversation contingencies more complex than those employed in the reply studies and well adapted for control of the problems associated with the tapes employed in the previous intermittent shock study (e.g., Lombardo, Weiss, \& Buchanan, 1972; Denton, Note 1; Feinberg, Weiss, Miller, Steigleder, \& Lombardo, Note 2). There were five practiced other-person confederates, always addressing a subject of the same sex, counterbalanced for experimental condition. In this way the replicability of the intermittent shock effect was assessed, free of any problems peculiar to the other-person tapes employed by Weiss, Williams, and Miller (1972).

\section{RESULTS}

Figure 1 shows effects in conversation which are analogous to intermittent shock effects in escape conditioning: Subjects disagreed with at the outset of only half of the trials still performed the instrumental response, but more slowly than subjects disagreed with at the outset of all trials. The effect is highly significant $[F(1,56)=9.07, p<.005]$, demonstrating the replicability of the intermittent disagreement effect and the independence of the effect from adventitious specifics of procedure. While the continuous and intermittent shock groups did not differ on the first trial (the intermittent group actually being slightly faster than the continuous), differentiation was very rapid, and there was no trace of an acquisition effect after the first two trials $(\mathrm{F}<1$ for each group). The replicability of the trials effect of the previous intermittent shock experiment has now been demonstrated, and the weight of this and other evidence appears to indicate an effect 


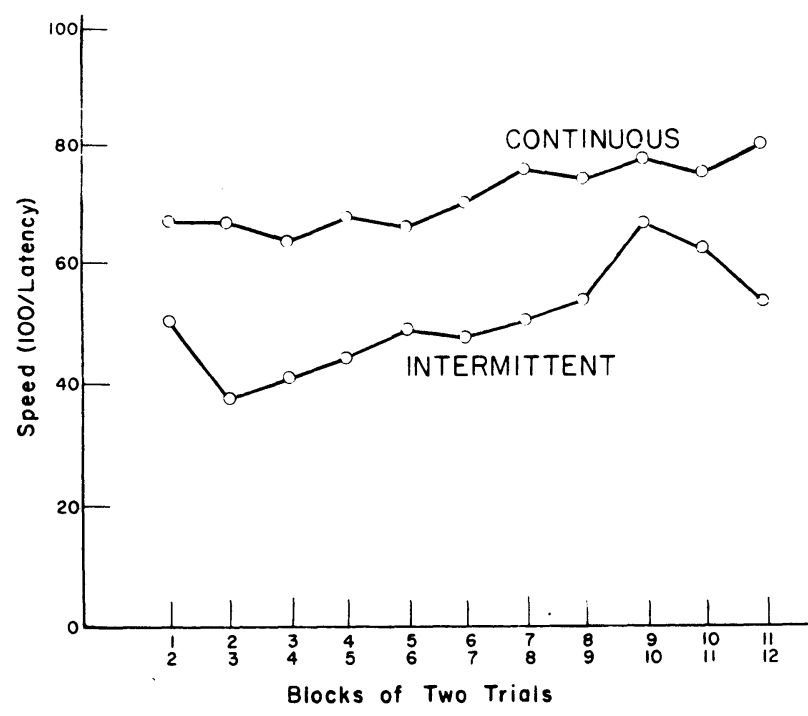

Figure 1. Intermittent and continuous shock: Effects of initial disagreement on half or all of the trials.

of uniformity of disagreement which is separable from the adventitious characteristics of a particular set of tapes.

\section{DISCUSSION}

The replicability of the intermittent shock effect strengthens the evidence of previous research in indicating that a basic form of interpersonal communication is analogous to escape rather than reward conditioning: The motivation is aversive and speaking in reply functions as negative reinforcement, like shock termination, rather than as positive reinforcement, like food. Moreover, this experiment pinpoints the locus of the aversive drive in the disagreeing opinion.

\section{REFERENCE NOTES}

1. Denton, D. A. Drive and reinforcement analogs in conversation. Unpublished doctoral dissertation, University of Oklahoma, 1975.

2. Feinberg, R. A., Weiss, R. F., Miller, F. G., Steigleder, M. K., \& Lombardo, J. P. Drive as a unifying concept in learned helplessness: Theory and experiments. Unpublished manuscript, University of Oklahoma, 1976. Available from
R. F. Weiss, Department of Psychology, University of Oklahoma, Norman, Oklahoma 73019.

\section{REFERENCES}

BYRnE, D. The attraction paradigm. New York: Academic Press, 1971.

BYRne, D., \& Clore, G. L., JR. Effectance arousal and attraction. Journal of Personality and Social Psychology, 1967, 6,(Monograph 4, Whole No. 638).

Byrne, D., Griffitt, W., \& Clore, G. L., JR. Attitudinal reinforcement effects as a function of stimulus homogeneityheterogeneity. Journal of Verbal Learning and Verbal Behavior, 1968, 7, 962-964.

Dollard, J., \& Miller, N. E. Personality and psychotherapy. New York: McGraw-Hill, 1950.

Franchina, J. J. Intertrial intervals and shock schedules in escape training. Journal of Comparative and Physiological Psychology, 1969, 67, 510-515.

Lamberth, J., Gouaux, C., \& Davis, J. Agreeing attitudinal statements as positive reinforcers in instrumental conditioning. Psychonomic Science, 1972, 29, 247-249.

Lombardo, J. P., Libkuman, T. M., \& Weiss, R. F. The energizing effects of disagreement-induced drive. Journal of Experimental Research in Personality, 1972, 6, 133-141.

Lombardo, J. P., Weiss, R. F., \& Buchanan, W. Reinforcing and attracting functions of yielding. Journal of Personality and Social Psychology, 1972, 21, 359-368.

Lombardo, J. P., Weiss, R. F., \& Stich, M. H. Effectance reduction through speaking in reply and its relation to attraction. Journal of Personality and Social Psychology, 1973, 28, 325-332.

Stapert, J. C., \& Clore, G. L. Attraction and disagreementproduced arousal. Journal of Personality and Social Psychology, 1969, 13, 64-69.

Weiss, R. F., BeCK, C. M., \& STICH, M. H. Correlated delay of reinforcement in the instrumental conditioning of conversational behavior. Psychonomic Science, 1972, 28, 211-212.

Weiss, R. F., Boyer, J. L., Colwick, J. T., \& Moran, D. J. A delay of reinforcement gradient and correlated reinforcement in the instrumental conditioning of conversational behavior. Journal of Experimental Psychology, 1971, 90, 33-38.

Weiss, R. F., Lombardo, J. P., Warren, D. R., \& Kelley, K. A. The reinforcing effects of speaking in reply. Journal of Personality and Social Psychology, 1971, 20, 186-199.

Weiss, R. F., Williams, M. J., \& Miller, C. M. Disagreement-induced drive in conversation: A social analog of intermittent shock in escape conditioning. Psychonomic Science, 1972, 29, 342-344.

(Received for publication August 10, 1976.) 